\title{
Discurso de recepção (*)
}

\section{Francisco Morato}

Quando ha pouco mais de trez mezes nos apresentámos perante vós e em succintos commentarios defendemos o projecto offerecido ao Governo de S. Paulo sobre Terras Devolutas, não conseguimos abafar os sentimentos que palpitavam agradecidos no intimo do coração com a expectativa que nos trouxera a grata nova de que tinheis em animo e elaboração o proposito de conferir-nos o titulo de membro honorario do Instituto da Ordem dos Advogados Brasileiros.

Oravámos commovido de vossa graça e liberalidade, sob a pressão da fortuna que nos envolvia e das referencias tropologicas com que nos saudára o nosso amavel presidente e confrade dr. Edmundo de Miranda Jordão.

Não logravamos alcançar como poderiamos vir a merecer tão excelsa dignidade e menos ainda como haveriamos de agradecel-a.

Convertestes em realidade o vosso designio por proposta dos drs. Carlos Castilho Cabral, Bruno de Almeida Magalhães, Rubens Ferraz, Miguel Calmon Vianna, Philadelpho Azevedo, Paulo Valladares, José de Alencar Piedade, Clovis Paulo da Rocha, Vicente Chermont de Miranda, Altino Moraes, Haryberto de Miranda Jordão, Justo de Moraes, Raul Gomes de Mattos, Oscar Saratva, Leonor de Mérocourt, Haroldo Valladão, Eurico de Sá Pereira, Octavio Gurgel

(*) Discurso do professor emerito Francisco Morato no Syllogeu do Rio de Janeiro, em sessão solene do Instituto da Ordem dos Advogados Brasileiros, ao ser recebido como sócio honorário. Conservou-se a ortografia do autor). 
de Rezende e Gennaro Vidal Leite Ribeiro. Mediante parecer previo e extremamente lisongeiro da Commissão de Admissão, composta dos drs. Otro GIL, Presidente e Relator, Thomas Leonardo e Miguel Paes do Amaral Pimenta, foi a proposta approvada em sessão plenaria de 6 do corrente mez.

Primastes de dupla gentileza; gentileza da materia, concedendo-nos a mais alta distincção que os Estatutos vos permittem outorgar e nelles se reservam aos graduados em direito de excepcional merecimento; gentileza do modo, adherindo ao parecer da Commissão de fazer approvar a proposta por acclamação unanime.

Hoje, na cerimonia da investidura official da dignidade, queremos antes de mais nada exprimir nosso reconhecimento a cada um dos directores do Instituto, dos proponentes da idéa, dos membros da Commissão e dos socios em geral pela tunica tão invejada e encarecida com que nos investem; queremos depois vos exorar particularmente para que vossa amizade nos acompanhe em todos os lances da vida e para que não nos desampare vossa benevolencia, quanta havemos mister neste momento.

Enche-nos de orgulho a inscripção de nosso nome na galeria dos membros honorários do Instituto, ao lado de seis varões insignes na esphera da intellectualidade, á frente dos quaes, em relevo fulgurante, como centro planetario dos astros da jurisprudencia, a figura desse leigo canonizado das lettras, emulo de Teixeira de Freitas e Lafayette, um dos mais fecundos e inspirados cinzeladores do formoso e tradicional quadro do direito patrio - o nosso mestre e querido amigo Clovis Bevilaqua.

Transborda-nos a alma a circunstancia de terdes ido procurar o premiado da vossa benevolencia na fileira activa dos que militam nos prelios da justiça e de nos haverdes aureolado com as primicias do primeiro jurista nacional que entra para o quadro selecto de vosso cenaculo, sem ter exercido sua actividade principal nesta cidade maravilhosa, nesta Côrte, onde outr'ora luziam as pompas do Imperio 
e onde ainda hoje pontificam os gigantes do Palatinado da intelligencia.

Sentimo-nos para todo sempre escravizado de tamanha. distincção. O premio com que cingis os nossos pergaminhos de jurista militante é uma honra maior que quanto nos seria possivel encarecer nem imaginar; honra que se realça. na escolha do orador que designastes para nos receber - o dr. Philadelpho Azevedo -, a cujos talentos e affeição nos. estreitam relações de antiga e intima camaradagem, Sansão das hostes de Themis, eximio expoente da nova geração de jurisconsultos, ainda agora guindado ao mais alto Tribunal Judiciario do Paiz nas azas só e só de suas lettras e merecimentos.

Vêde quão abundante e generoso foi elle, carregando. nosso nome de immerecidos louvores e predicados.

Confessamo-nos verdadeiramente reduzido por sua bella oratoria.

A impressão que della acabamos de colher foi a mesma de surto e surpreza que nos salteou, ao ouvir pela primeira. vez nos chamarem de jurisconsulto.

Estavamos em aula de Direito Administrativo, quando nosso lente José Rubino de Oliveira, sempre faceto e perigoso na intelligencia, communicou aos alunos ter sabido, por noticia com que acertara em jornal academico, haver na. classe um jurisconsulto, a quem promettia por em provas e devidas contas. Alludia ironicamente a uma chronica em que um collega, á semelhança e maneiras do vosso orador, cobria-nos de epithetos laudativos.

Fomos affrontado de um susto e surpreza, que só nos deixou depois de submettido a acto e plenificado nas escaramuças regulamentares da Escola.

Era nos dias idos, como é nos instantes que batem, a. voz da consciencia a lembrar a realidade de nossa pequenineza e incompetencia para corresponder de perto a dotes. que se proclamam e imaginam engrandecidos com aquelle relevo e miragens com que de longe nos vem á mente tudo. quanto é distante no tempo e no espaço. 
Gentil e formoso de começo a fim, no fundo e na forma, traçou o eminente orador os passos capitaes de nossa vida de modesto intellectual, não se dedignando de considerar-nos como advogado, como jurisconsulto, como professor, como politico, como escriptor, como apaixonado da lingua e das lettras classicas. Alludiu ao nosso exercicio nas luctas do fôro, na banca de consulta, na cathedra de lente, na mesma cathedra onde passamos alguns dos mais logrados annos de nossa vida e onde preleccionaram os vultos inconfundiveis de Ramalho, João Monteiro, João Mendes e Estevam de Almeida. Referiu-se á nossa direç̧ão da Faculdade de Direito de S. Paulo, o glorioso convento de São Francisco, hoje restaurado nas magnificencias da architetonica moderna, mas sempre immutavel, querido e admirado na magestade do seu passado, na grandeza de sua missão historica, no brilho de suas tradições culturaes. Salientou nosso papel de fundador e presidente por varios biennios do Instituto da Ordem dos Advogados de S. Paulo, de precursor, ao lado do egregio Carvalho Mourão, da oralidade processual, reforma que patrocinámos no Congresso Nacional de Direito Judiciario de 1936, quebrando ou reduzindo a resistencia assaz generalizada entre os congressistas. Não se esqueceu de que fomos um dia envenenado da politica e do que fizemos no Parlamento ao lado de Bergamini e outros paladinos da democracia, levantando o movimento que obliquamente provocou o novo panorama e scenario nacional. Não se esqueceu do que passamos na politica, nessa arte madrasta, em que a unica coisa de edificante que conseguimos patentear aos nossos concidadãos foi que, a despeito dos golpes que nella se padecem, não é facil enclausurar a consciencia, abater o animo, mudar as idéas e emmudecer a palavra de um jurista fiel á nobreza e força espiritual do seu officio; o que aliás - si licet parva componere magnis - seria tão só uma lembrança da licção e exemplo de Papiniano, que, ouvindo de Caracala a ordem de fazer a apologia do fraticidio que o monstro commettera, preferiu render a cabeça ao despota a macular seu nome, no juizo da posteridade, 
com o opprobio de uma apostasia: Senhor! menos difficil é commetter do que justificar um fraticidio - non tam facile parricidium excusare quam posse fieri.

Certo, Senhores do Instituto, que todos estes attributos e circumstancias teriam influido no vosso espirito, ao me adornardes com os galões e insignia de membro honorario deste secular e elevado sodalicio.

Como já tivemos occasião de dizer neste mesmo recinto, ao deixar jubilado a cathedra de Direito Judiciario Civil, conferiram-nos nossos confrades da Faculdade de Direito de S. Paulo, o titulo de professor emerito, então summamente honroso, pois era o primeiro e o unico que se concedia. Recebemos da mocidade uma das mais estrondosas manifestações que têm vibrado nas Arcadas daquelle Templo dias Iuzes. Fomos homenageado em grandioso banquete, no qual se reuniram para aclamar o nosso nome e por subir-nos a alturas a que nunca aspiramos, congregados, na phrase do orador official, em uma como encruzilhada de todas as classes, missionarios de todos os ramos scientificos, embaixadores das actividades economicas, representantes de todas as correntes politicas e religiosas, descendentes dos mais antigos brazões de Piratininga, fundadores de novas e promissoras estirpes; banquete do cosmopolitismo paulista em que o verbo sempre imaginoso e fecundo de Alexandre MarconDES FILHo, em nome dos manifestantes, nos comparava a um restatuario sobre marmore humano e em delicada antonomasia nos consagrava Miguel Angelo das nossas juventudes.

Agora na outorga de vossa benevolencia, si por um lado houveram influido todos os respeitos e departamentos de nossa actividade, por outro teria predominado a razão de sermos advogado e os lances dè nossa carreira nesta especialidade, de todas a mais difficil, em these e em regra mais opulenta nas claridades que dadivosa nas graças - clarius quam gratius officium, segundo o lemma do Instituto de S. Paulo.

No circulo das funcções geraes do jurista, o papel do advogado é porventura o mais penoso e precario, pois que 
aos dotes e predicados que a todos competem junge e reclama os que lhe são peculiares.

Não nos fatigaremos de encarecel-o e de repetir o panegyrico que ao proposito do thema havemos frequentemente escripto e pronunciado.

O jurista é o levita da justiça e a justiça, na sua expressão divina e mundana, é o eixo em torno do qual revoluteiam todos os interesses da humanidade, chave dessa harmonia maravilhosa que o genio de LeIBNITz denominou do prestabelecida pela bondade e sabedoria do Creador.

Artifice do jus condere, interprete, guarda e defensor do jus conditum, cumpre-lhe accumular cabedal de variados conhecimentos e disciplinas, de manejo impeccavel da logica, de completa intelligencia das leis escriptas, de sciencia dos principios geraes, eternos, superiores a circumstancias de tempo e espaço, universaes, communs ao genero humano - compendio do Direito Natural; de adestramento nas regras da hermeneutica e, acima de tudo, de maestria em submetter os casos multifarios da vida quotidiana, as construcções legislativas, as obras de doutrina, as provisões dos regimentos á regencia de um corpo homogeneo e inteiriço de preceitos, estreitados em logico travamento scientifico e tocados desse espirito de unidade, systema e generalização que caracteriza a obra dos grandes engenhos e a technica dos grandes profissionaes.

Batalhador na esphera da intellectualidade, cumpre-lhe ademais afoguear o espirito, a palavra e a penna no estudo, contemplação e pratica de tudo quanto é bello, delicado e grandioso; brunir as imagens, primores, ornamentos, elegancia e finuras que se defrontam no cuidado da forma, na elevação do pensamento e na familiaridade das bellaslettras, das bellas-artes e das fontes inexhaustas e inexhauriveis da esthetica e da eloquencia.

A todas estas prendas, virtualidades e dons está adstricto o advogado pelas obrigações communs do officio.

Si quizerdes esboçar a sua figura, exclama PaILlet, exornai um homem de todos os dotes de caracter $\theta$ de espi- 
rito, admitti que tudo haja visto, aprendido e retido, que haja laborado longos annos sem repouso, que seja simultaneamente litterato, critico e moralista, que tenha a experiencia de velho, o ardor de jovem e a memoria de creança, talvez ahi logreis vel-a completa.

Não se confunde o advogado com o jurisconsulto, com o professor ou com o escriptor, que trabalham no remanso do gabinete, na prelazia da cathedra ou no retiro das lucubrações do cerebro, desvincilhando questões de direito, dando licções á mocidade, construindo ou repetindo doutrinas de jurisprudencia; mas com uns e com outros deve competir em erudição, avantajando-se na solercia e promptidão, pois, não podendo o theoria ser casuistica e formular regras para a infinidade proteiforme das hypotheses occorrentes, força lhe é jogar com os principios, que são tudo no direito, e a cada caso dar a applicação insita no pensamento, conteúdo e obrigatoriedade da norma.

Não se confunde com o juiz, porque, embora sejam ambos factores do equilibrio dos direitos e do imperio da justiça, varia a missão de um e do outro na natureza das funcções e no modo das operações. Em nome da lei, o advogado postula, o juiz delibera; um, orgão da justiça militante, outro orgão da justiça imperante; em paraphrase ciceroneana, a lei é o magistrado mudo - lex magistratus mutus, o juiz, a lei fallando - magistratus lex loquens, o advogado, a lei militando - advocatus lex militans.

Na conferencia de Curityba, a que com inexcedivel garbo referiu-se vosso orador, salientámos como divergem as actividades e pendores entre juizes e advogados; as actividades variando na differença entre o imperio e a postulação, os pendores visando por uma banda á realização da vontade da lei e por outra á da vontade das partes; uns e outros objectivando a victoria da justiça.

A divergencia das vocações, methodos e actividades im. plica a diversidade do officio e a diversidade do officio, a diversidade da ethica. 
0 advogado, como alumiador do direito e organizador dos planos das batalhas judiciarias, apanha as questões ainda virgens de qualquer illustração, examina-as em seus multiplos aspectos, ajusta-as ás normas juridicas, orienta-as, instrue-as e condul-as até final, produzindo não raro dissertações exhaustivas, que se perdem na poeira dos cartorios ou nas galas de sentenças sobre ellas debuxadas, apaixonando-se pelas causas, gosando com os clientes as alegrias da victoria e com os clientes padecendo as decepções dos insuccessos. E um luctador, em combate incessante contra a habilidade, astucia e surprezas do adversario, contra a deslealdade, ciume e impolidez de collegas mal educados, contra a incompetencia, desidia, teimosia e até muitas vezes inveja dos maus juizes. E ainda uma victima consciente e resignada, um heroe deixado de si mesmo, que, por um lado, não raro colhe do cliente o esquecimento ou as punhaladas do estylete da ingratidão e por outro, tem de carregar perpetuamente com a hostilidade do litigante contrario. Porque a nossa profissão tem isto de extraordinariamente singular, de supinamente significativo: o litigante vencido esquece cedo os rancores contra o litigante vencedor, com elle reata relações, reconcilia-se, porventura reconhecendo que o direito de pleitear é tão sacrosanto para um quanto para outro; mas não esquece jamais o odio contra o advogado vencedor, em quem não reconhece justificativa para intervir num pleito a que não é chamado por interesse directo e a quem reputa suppositiciamente unico responsavel por sua derrota.

$\mathrm{O}$ juiz tem funções mais suaves, comquanto, sob certo ponto de vista, de maior responsabilidade.

Á parte a despreoccupação do successo economico da actividade, assegurado pela fixidez dos vencimentos, e a circumstancia de ser bastante mais facil criticar e seguir trilha batida, tomando partido por este ou aquelle lado, do que produzir, articulando ou desarticulando controversias, mantem-se indifferente aos embates que se ferem ao seu lado e ás manifestações de jubilo ou afflicção dos litigantes. 
Comquanto, porem, variando nos pendores, injuncções e actividades, juizes e advogados andam irmanados na servidão do mesmo ideal e justiça. O juiz é um orgam sereno e imparcial na applicação da lei, o advogado um orgam ardente e apaixonado na postulação da justiça.

É interessante vêr, Senhores, como nas eras dos faustos e esplendores de Roma, Cicero, o creador do substantivo singular advogado, tratava o profissional que envergava a toga desta dignidade e sob suas dobras alçava o verbo nas pugnas do Forum.

Em numerosas de suas obras e discursos - De Oratore, Orator ad Brutum, Pro Murena, De Optimo Genero Oratorum, Pro Archia -, a famosa aguia romana canta hymnos ás doçuras das lettras e realça os dotes de eloquencia, de sabedoria, de nobreza, de caracter que deve ter todo orador; orador, porque sendo áquelle tempo essencialmente oral o procedimento, eram os debates reservados aos que possuiam o dom da palavra.

Aconselhava-o a inspirar-se nas fontes elevadas e puras, subindo ao modelo divino que era Platão, para que a philosophia, a dialectica, a linguagem e a arte lhe aperfeiçoassem a eloquencia, o talento das generalizações, o vigor do pensamento, a supremacia do raciocinio, a habilidade da commoção. Não lhe bastava vestir de galas a elocução, agradar e convencer; cabia-lhe ainda esgrimir com paixão, provocando gemidos, lagrimas, transportes de admiração e rompantes de colera. No estylo impunha-se-lhe agglutinar em chromo admiravel as bellezas da pintura, a rigidez da philosophia, as doçuras da musica.

Sem desdenhar os ornamentos e louçanias de linguagem, o estylo moderno do fôro tem de ser conciso, discreto, breve e substancial, como breves e resumidas devem ser todas as orações.

A synthese é que é bella e difficil; a synthese é que agrada e convence. Por mais harmonioso e sublime que seja, não conseguirá o orador prender e agradar o auditorio com allocuções extensas. Não fazem boa consequencia os derra- 
mamentos da exposição, o facil entendimento da materia e o deleite dos ouvintes. Por uma fatalidade de biologia mental, as longuras estiolam as faculdades emotivas e obumbram a intelligencia.

Hoje em dia sobretudo, com a oralidade processual, é de mister affeiçoar o estylo ao novo systema de procedimento, tanto para os orgams judicantes quanto para os orgams auxiliares.

Ha pouco, em erudita monographia sobre Recurso de Revista, profligou um brilhante magistrado paulista o que elle denominou os longos aranzeis dos advogados. Foi justo, mas para ser completo na justiça devia tambem profligar os aranzeis dos julgadores, porque no grupo destes e daquelles alguns ha que deslizam nas leis da brevidade e clareza. Em apoio de sua critica invoca Fabroguettes - La Logique Judiciaire -, quando devia tambem invocar o escripto francez na bella regra que traça aos sentenciadores - le plus de choses dans le moins de mots.

Razões nenhuma justificam disparidades e preferencias neste topico. O que sobe de ponto entre nós, pois, a par e passo que ao juiz é facultado fallar ou ler quanto tempo lhe apraza, é constrangido o advogado, ainda mesmo versando assumpto que pela complexidade e alta indagação reclama dilatado tratamento, a discursar apertado nos limites de 15 ou 20 minutos. A limitação de tempo que se lhe impõe, é um preceito parcialissimo e exdruxulo, cuja permanencia deve a Ordem combater e que devemos verberar até que se elimine dos regimentos ou se converta em regra mais intelligente, calada sobre criterio paritario.

Viria a ponto como de bom conselho dar aos juizes e presidentes de tribunaes a attribuição de dirigir os debates, forçar o que falla a cingir-se á materia e a evadir divagações, restringindo-lhe ou augmentando-lhe o tempo, conforme esteja dizendo coisas inuteis ou produzindo allegações que façam a bem da verdade e da causa. Seria um pouco de arbitrio, mas arbitrio indispensavel, que não mereceria censura, porquanto o magistrado representa no processo a sobe- 
rania nacional, actuando em nome de um dos mais importantes poderes politicos do Estado. Mesmo na vigencia e limitação do actual prazo declarado improrogavel pelo texto, seria de desejar se lhe desse interpretação mais espiritual e equitativa.

Para quem conhece a linguagem juridica e as regras da processualistica sobre termos, prazo improrogavel não quer dizer prazo fatal; entre um e outro a differença é sensivel, no conceito e nas consequencias. O prazo se estende improrrogavel na normalidade das circunstancias.

Tendo o processo por fim descobrir a verdade, para boa applicação da lei, seria realmente estupefaciente não pudesse o juiz dispensar na lettra do texto e por amôr á expressão muda da palavra houvesse de contravir o seu objetivo fundamental.

Discorrendo acerca da funcção da equidade na racionalização do texto, exemplifica o summo Santo Thomaz que si a lei manda restituir o deposito, isso se entende nos casos normaes, porque, si o depositante de uma espada a reclama em accesso de loucura ou para luctar contra a patria não deve restituil-a o depositario - bonum est, praetermissis verbis, sequi id quod poscit justitiae ratio ret communis utilitas.

A sciencia do advogado tem de ser completa, não no sentido de abarcar toda a orbita dos conhecimentos humanos, mas no de especializar-se no objecto do officio e no discorrer a traços largos sobre todos os assumptos que lhe possam ser propostos.

Seria ridiculo pretender fazel-o mestre de omni ne scibili, á semelhança de um Pico de Mirandola, ou expôl-o a hombrear com essas figuras a que a ironia romana rendia cultos annuaes ie que na gamma dos vaidosos trazem a legenda de Petrus in cunctis, nihil in omnibus.

A natureza, entretanto, da profissão, trazendo em seu bojo e continencia os mais variados objectos, forçando-o a uma visão continua e peripherica dos assumptos, dá-lhe uma gymnastica e flexibilidade de espirito que o habilita a dizer 
com elegancia e proficiencia de todas as coisas, posto que estudadas por necessidade e de momento.

Corroborando este ponto de vista, advertia Cicero que Aratus, sem saber astronomia, descreveu em versos admiraveis os movimentos dos astros e os phenomenos celestes.

Sobre os requisitos de probidade, polidez, desprendimento e independencia, é de extremo rigor a deontologia. Compendia-os em canones severos o Codigo de Ethica de S. Paulo, que tivemos a honra de redigir na esteira das tradições de nossos auditorios, nas licções de Ramalho, João Monteiro, Strikio e outros interpretes nacionaes e peregrinos, na bella disciplina do fôro francez e nos Canons of Ethics, for Lawers adopted by the American Bar Association.

$\mathrm{E}$ de rigor guardar os advogados as observancias $\mathrm{da}$ probidade e desprehendimento, não rejeitando por consideração alguma pessoal a causa dos indefesos e opprimidos, não a retardando por motivo de lucro ou malicia e tendo sempre presente que a advocacia é ramo da administração publica e não commercio para fazer dinheiro; fazer timbre de cortezia e urbanidade nas relações com os adversarios e litigantes; tratar os juizes com o maior respeito, modestia e independencia, sem dispensar egual tratamento por parte delles e sem esquecer que uns e outros collaboram na mesma obra e servem a mesma causa, com egual nobreza de officio.

Em thema de hombridade, não se perdoaria olvidasse o profissional nossa posição na hierarchia dos intellectuaes e a conducta que devemos manter, imposta pela nobreza das lettras e das funcções.

Ha menos de dois mezes, em Reminiscencias Litterarias estampadas no JORNAL DO COMMERCIO, escreveu EDMuNDo Lins que a adulação foi sempre o nectar dos grandes homens e uma doença que acompanha insistentemente os intellectuaes. Para comprovar tão extranha proposição, cita Ovidio, Horacio e Virgilio, aos quaes passa o diploma de engrossadores, de avaccalhados poderia ter dicto com maior dureza, si quizera usar de um neologismo popular, que o fino CARLOS DE LAET achava bem formado para o caso e que segu- 
ramente seria invento dos cariocas, sempre fecundos e habilidosos na inventiva de epithetos e jocosidades.

Em que pese á latinidade do insigne litterato e jurista mineiro, parece que as passagens citadas de Horacio e VirGilio nada fazem ao caso e que, relativamente ao topico dos Tristes, onde o poeta chama Deus a Augusto, vem a lanço lembrar que Ovidio compoz suas elogias em forma de supplicação, quando em exilio.

Não; a lisonja é um nectar dos caracteres pusillanimes; é um estigma das baixas lettras e não das lettras que illustramos.

Senhores. No seio deste Instituto, Metropole de seus. congeneres dos Estados, que se inaugurara solemne e promissor em 1843 pelo verbo de Montezuma e que hoje prosegue prosperado e prestigioso ás mãos e presidencia de MIRANDA JORDÃo, reiteremos o proposito, retemperemos o animo e vibremos para a frente as vozes que vem tangidas do passado, de jamais esmorecer no orgulho de nossos pergaminhos, no esplendor de nossos ideaes e no desempenho de nossa missão apostolica.

O momento é de trevas e angustia; a selvageria de um grupo de monstros cobre o mundo de lagrimas, de infortunios e de exterminio.

É porventura a mais barbara e infanda crise que registram os fastos das dores è do anniquilamento. Tudo tomba e veste-se de lucto, inclusive os monumentos e testemunhos da cultura universal.

O eclypse ha-de passar; a historia está cheia destes collapsos.

Susta-se, interrompe-se, mas não se quebra a continuidade da civilização; opprimem-se, martirizam-se, aviltam-se os povos e as nações, mas não se rompe a lei divina da perpetuidade da grei humana.

Si a tormenta vae durando demasiado, isso são instantes. na successão dos seculos. Esperemos confiados o futuro; a dilação da esperança será compensada pela suavidade infinita da paz. 
Sus! mestres e confrades. No meio da conflagração geral, por entre a chama e o fumo que nos envolvem, continuemos resolutos e intrepidos na ufania de nosso papel e na defesa do direito.

Não ha temporal que nunca se acabe. De tudo, como diria Castilho Antonio, faz a Providencia materiaes para suas edificações. 